\title{
BMJ Open The Dutch Parelsnoer Institute Cerebrovascular Disease Initiative: a retrospective study of the effects of integrating clinical care and research on costs and quality of care in patients with ischaemic stroke
}

\author{
Liselore A Mensing, ${ }^{1}$ Jaap Kappelle, ${ }^{1}$ Julie E Buijs, ${ }^{2}$ Gert-Jan Luijckx, ${ }^{2}$ \\ Hendrik Koffijberg, ${ }^{3}$ Gerhard A Zielhuis, ${ }^{4}$ Ynte M Ruigrok ${ }^{1}$
}

To cite: Mensing LA, Kappelle J, Buijs JE, et al. The Dutch Parelsnoer Institute Cerebrovascular Disease Initiative: a retrospective study of the effects of integrating clinical care and research on costs and quality of care in patients with ischaemic stroke. BMJ Open 2019;9:e028290. doi:10.1136/ bmjopen-2018-028290

- Prepublication history and additional material for this paper are available online. To view these files, please visit the journal online (http://dx.doi. org/10.1136/bmjopen-2018028290).

Received 30 November 2018

Revised 13 July 2019

Accepted 17 July 2019
Check for updates

(C) Author(s) (or their employer(s)) 2019. Re-use permitted under CC BY-NC. No commercial re-use. See rights and permissions. Published by BMJ.

For numbered affiliations see end of article.

Correspondence to Liselore A Mensing; L.A.Mensing-3@umcutrecht.nl

\section{ABSTRACT}

Introduction The Dutch Parelsnoer Institute (PSI) is a collaboration between all university medical centres in which clinical data, imaging and biomaterials are prospectively and uniformly collected for research purposes. The PSI has the ambition to integrate data collected in the context of clinical care with data collected primarily for research purposes. We aimed to evaluate the effects of such integrated registration on costs, efficiency and quality of care.

Methods We retrospectively included patients with cerebral ischaemia of the PSI Cerebrovascular Disease Consortium at two participating centres, one applying an integrated approach on registration of clinical and research data and another with a separate method of registration. We determined the effect of integrated registration on (1) costs and time efficiency using a comparative matched cohort study in 40 patients and (2) quality of the discharge letter in a retrospective cohort study of 400 patients.

Results A shorter registration time (mean difference of $-4.6 \mathrm{~min}, \mathrm{SD} 4.7, \mathrm{p}=0.001$ ) and a higher quality score of discharge letters (mean difference of 856 points, SD 40.8, $p<0.001$ ) was shown for integrated registration compared with separate registration. Integrated registration of data of 300 patients per year would save around $€ 700$ salary costs per year.

Conclusion Integrated registration of clinical and research data in patients with cerebral ischaemia is associated with some decrease in salary costs, while at the same time, increased time efficiency and quality of the discharge letter are accomplished. Thus, we recommend integrated registration of clinical and research data in centres with high-volume registration only, due to the initial investments needed to adopt the registration software.

\section{INTRODUCTION}

The Dutch Parelsnoer Institute (PSI) is a collaboration between all eight university medical centres in the Netherlands and was established in 2007 by the Netherlands
Strengths and limitations of this study

- Our comparative matched cohort study was performed by local professionals experienced in stroke care who were blinded for case characteristics.

- It was unfeasible to record registration of clinical and research data in real time.

- The quality of the discharge letter was based on quality parameters validated by the expert opinion of a substantial, interdisciplinary group of recipients of these kinds of discharge letters recruited from different regions to avoid biased scores.

Federation of University Medical Centres. Currently, 17 large clinical cohorts are formed for a variety of diseases with prospective, standardised collections of comprehensive clinical data and biomaterials. ${ }^{1-3}$ A major ambition is to integrate clinical care and scientific research by building a strong collaborative infrastructure allowing prospective uniform collection of clinical data and biomaterials within the context of healthcare. ${ }^{1}$

One of the 17 selected diseases within PSI is cerebrovascular disease. Three of the participating university medical centres in this PSI Cerebrovascular Disease Consortium have integrated the registration of data for clinical and research purposes (ie, entering clinical data and additional research data simultaneously in the electronic patient record). Other centres register the data for clinical purposes separately from those for research purposes (ie, the clinical data are entered first in the electronic patient record, and in a later stage, the research data are added to these medical files or entered in a separate research database). All centres are specialised stroke 
centres treating the same type of patients. We hypothesised that integrated registration is more efficient in terms of cost savings and time savings, while at the same time clinical care will benefit because of improved data quality and completeness. The current project aimed to evaluate the effects of integrated registration of clinical and research data on costs, time efficiency and quality of the discharge letter in the Dutch PSI Cerebrovascular Disease Initiative.

\section{METHODS}

We selected all consecutive patients with cerebral ischaemia from 2011, 2015 and 2016 (see paragraphs in the Study design section) who gave informed consent to participate in the Dutch PSI Cerebrovascular Disease Consortium at the University Medical Centre Utrecht (UMCU) and at the University Medical Centre Groningen (UMCG). These centres were selected based on their focus on cerebrovascular disease and the use of a different registration method. In the UMCU (further referred to as centre A) registration of clinical and research data is integrated, while in the UMCG (centre B) registration of clinical and research data is performed separately. Both centres are university medical centres and therefore combine clinical care with scientific research; centre A has a Joint Commission International (JCI) accreditation and around 1000 beds and Centre B is ISO certified and has around 1300 beds. We determined the effect of integrated registration of clinical and research data on (1) costs and time efficiency, and (2) quality of the discharge letter.

\section{Patient and public involvement}

Patients and/or the public were not involved in the design or conduct of this study.

\section{Costs and efficiency}

\section{Study design}

A matched cohort study was performed to determine how much time clinicians and research nurses need to register both clinical and research data, comparing two conditions: integrated registration versus separate registration. Registration of clinical data comprised both the medical chart and the letter of discharge. Time investment was subsequently converted to salary costs. In addition, we estimated the costs to implement a computer program with software that facilitates the integrated registration. We investigated what would happen (as counterfactual) if clinical and research data of patients from centre $\mathrm{A}$ were registered at centre $\mathrm{B}$, and vice versa. Based on an expected difference in registration time of 10 minutes, a power of $80 \%, 5 \%$ significance and an SD of 10 with two-sided testing, we calculated a sample size of 20 patients in each group. We selected 20 patients treated in centre B in 2016 with a fair distribution of the major factors associated with the administrative burden (ie, time to register and time to produce a discharge letter). The most prominent factors that were used for the selection of patients were age $(<50,50-70$ and $>70$ years $)$, the National Institutes of Health Stroke Scale (NIHSS) score $^{4}$ and the Trial of Org 10172 in Acute Stroke Treatment (TOAST) classification. ${ }^{5}$ The NIHSS produces a score indicating the severity of the stroke (' $0-5$ ' indicating moderate deficit and ' $>5$ ' indicating a severe stroke), ${ }^{4}$ and the TOAST classifies ischaemic stroke in subtypes based on aetiology. ${ }^{5}$ The yearly distribution of TOAST subtypes in centre A was used as reference for selection ('large vessel disease', 25\%; 'cardioembolism', 25\%; 'small vessel disease', 20\%; 'undetermined cause', $20 \%$; and 'other determined cause' $10 \%$ ). In addition, we selected $50 \%$ of patients in each of the two NIHSS categories and finally selected the proportion of patients per age category according to the distribution per year in centre A ('<50 years', 20\%; '50-70 years', $40 \%$; and '>70 years' $40 \%$ ). We then matched the selected cases from centre B to cases from centre A, making sure that each matched case pair was comparable in age, NIHSS score and TOAST classification. To check whether the matching was successful, we compared case severity within the matched pairs, as determined by the number of additional investigations during hospital stay and the number of in-hospital days. A match was considered successful if both numbers were in comparable ranges.

\section{Data collection}

A final-year neurology resident (JB), who was familiar with the clinical infrastructure and electronic patient record of both hospitals, was asked to perform the integrated registration and to generate discharge letters for patients from centre $\mathrm{A}$, and to perform the separate registration of research data and to write discharge letters (with a minimum number of predefined items comparable with centre A) for patients from centre $\mathrm{B}$. This resident was blinded for case characteristics, including age, NIHSS score and TOAST classification. Registration was performed in an offline version of the electronic patient record and research application in both centres. See online supplementary 1 for a copy of the registration form. Time of registration was registered in minutes by one of the authors (LAM).

Afterwards, a specialised research nurse from each centre was asked to complete the registration of research data and to perform subsequently a quality check on these data, according to routine practice in that centre. Both research nurses were equally experienced. Additional registration and data check were also timed by one of the authors (LAM). Salary information was based on national agreed salaries for final-year neurology residents and trained research nurses, which were comparable for both centres. Costs for development and implementation of an integrated registration programme were estimated by the information technology department of centre A. Costs of maintenance of this computer program and depreciation were unavailable and hence were not included. 


\section{Statistical analysis}

The mean difference of registration time in minutes with corresponding SD was calculated and evaluated with an independent samples t-test, comparing integrated registration with separate registration. In addition, the registration times for the resident and the research nurses were compared separately, although the amount of data registered by the resident and research nurses differed between both centres (see previous paragraph in the Data collection section). The mean difference in costs per registration was calculated by multiplying the mean difference in registration time for residents and for research nurses by their salary costs per minute for both groups, and then adding them together.

\section{Quality of the discharge letter \\ Study design}

To compare the quality of the discharge letters between centre $\mathrm{A}$ and centre $\mathrm{B}$, we performed a retrospective cohort study with four cohorts to get an empirical impression of the potential effect on the quality of healthcare processes adjusted for centre-specific and time-specific effects not related to the mode of data registration. In this way, the added value of the integrated registration relative to separate registration could be estimated. Discharge letters of patients with cerebral ischaemia from centre A in 2015 (clinical care and research integrated) were compared with discharge letters of patients with cerebral ischaemia from centre B in 2015 (clinical care and research separate), from centre A in 2011 (clinical care and research separate) and from centre B in 2011 (clinical care and research separate).

A quality score was developed to determine the quality of the discharge letters. To develop this score, an online survey was sent to an expert panel of 132 academic and non-academic Dutch neurologists, general practitioners, rehabilitation specialists and specialists in geriatric medicine from the referral regions of both centres A and B. Selection of this expert panel was based on affinity with cerebrovascular diseases in daily practise. The members of the panel had to assess 26 predefined items as being 'relevant' or 'not relevant' for being included in discharge letters of patients with cerebral ischaemia. These 26 items were derived from the current discharge letters in both centres, and included items on the clinical presentation and prognosis of the patients and on the risk factors for cerebral ischaemia.

\section{Data collection}

A total of 100 consecutive patients were selected from each cohort, starting on 1 January. Baseline information and discharge letters were retrieved from the electronic patient records. Scoring of the items of the discharge letters was done independently by two observers (one of the authors (LAM) and a medical student) and interrater variability was calculated. Conflicting results were discussed in a consensus meeting.

\section{Statistical analysis}

Items indicated in the survey as not very relevant $(<25 \%$ of respondents considered this item relevant) were scored with 0 points. Moderately relevant items $(25 \%-75 \%$ of respondents considered this item relevant) received a weight of 50 points. Highly relevant items $(>75 \%$ of respondents considered this item relevant) were weighted with 100 points. Summation of these weighted scores for all items produced an overall score reflecting the quality of the discharge letter. Scores for discharge letters with missing items were standardised according to the relative contribution of that missing item to the maximum score. We primarily compared data from centre A and centre B obtained in 2015, calculating a mean difference in quality score with corresponding SD and evaluating this with an independent samples t-test. In addition, we compared the data for each centre for the year 2015 with the data from 2011. An inter-rater variability was calculated using Cohen's kappa statistic.

\section{RESULTS}

\section{Costs and efficiency}

The amount of data registered was the same in both centres, but the division of data processing by the resident and the research nurse differed between centres. In centre A, the resident performed most of the registration and the research nurse checked only for the completeness of data, whereas in centre $\mathrm{B}$, the resident performed the registration of clinical data and the research nurse

Table 1 Baseline characteristics of cases included in the matched cohort study

\begin{tabular}{|c|c|c|}
\hline Baseline characteristics & $\begin{array}{l}\text { Care and } \\
\text { research } \\
\text { integrated } \\
\mathrm{n}=20\end{array}$ & $\begin{array}{l}\text { Care and } \\
\text { research } \\
\text { separate } \\
\mathrm{n}=20\end{array}$ \\
\hline Women, n (\%) & $12(60)$ & $9(45)$ \\
\hline \multicolumn{3}{|l|}{ Age } \\
\hline$<50$ years, $\mathrm{n}(\%)$ & $4(20)$ & $3(15)$ \\
\hline $50-70$ years, $\mathrm{n}(\%)$ & $8(40)$ & $11(55)$ \\
\hline$>70$ years, $n(\%)$ & $8(40)$ & $6(30)$ \\
\hline \multicolumn{3}{|l|}{ TOAST classification } \\
\hline Large vessel, n (\%) & $5(25)$ & $5(25)$ \\
\hline Cardioembolic, n (\%) & $5(25)$ & $5(25)$ \\
\hline Small vessel, $\mathrm{n}(\%)$ & $4(20)$ & $4(20)$ \\
\hline Other determined, n (\%) & $2(10)$ & $2(10)$ \\
\hline Undetermined, n (\%) & $4(20)$ & $4(20)$ \\
\hline NIHSS score <6, n (\%) & $9(45)$ & $9(45)$ \\
\hline $\begin{array}{l}\text { Number of investigations, mean } \\
\text { (SD) }\end{array}$ & $5.2(1.7)$ & $4.8(1.5)$ \\
\hline Days in hospital, mean (SD) & $5.6(2.8)$ & $4.9(3.2)$ \\
\hline
\end{tabular}

NIHSS, National Institute of Health Stroke Scale; TOAST, Trial of Org 10172 in Acute Stroke Treatment. 


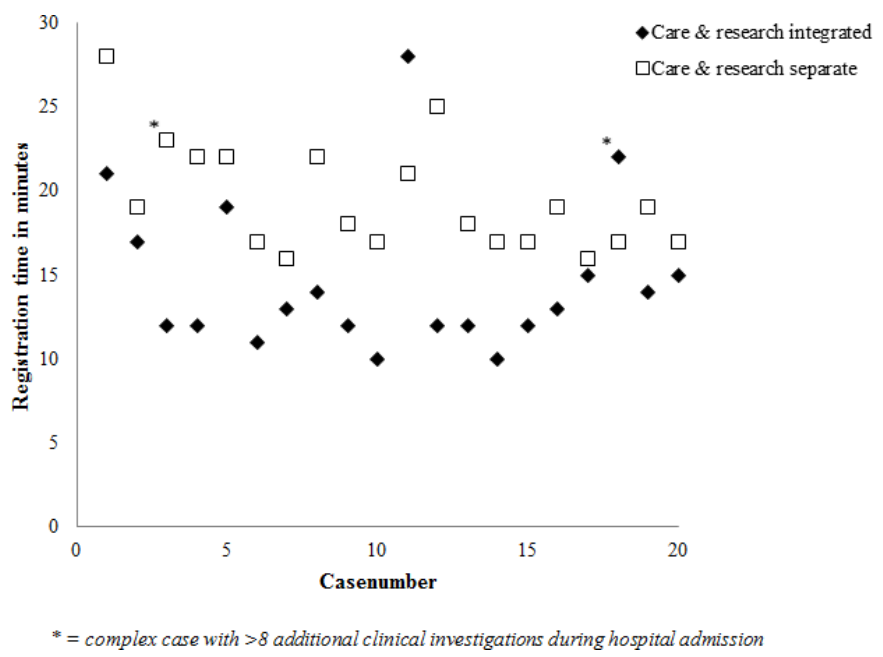

Figure 1 Registration time (in minutes) for 20 matched pairs of cases abstracted from the files of two participating centres, with integrated registration versus separate registration.

performed the registration of research data. This is a consequence of different systems, namely, separate or integrated registration, and of different organisational contexts determining the task division. Baseline characteristics of the 40 matched patients are shown in table 1. All patients were matched successfully for TOAST classification and NIHSS score, whereas we were not able to establish a perfect match for age (table 1).

Figure 1 demonstrates the distribution of registration time per matched case for both centres. In most pairs, the registration time of integrated registration of clinical and research data was lower than the registration time of separate registration (mean difference of $-4.6 \mathrm{~min}, \mathrm{SD} 4.7, \mathrm{SE}$ 1.3, $\mathrm{p}=0.001$; table 2). Exceptions were two complex cases with more than eight additional investigations.

On comparing the registration time of the residents and research nurses separately, the registration time using integrated registration was again shorter compared with that using separate registration: for residents, a mean difference of $-3.4 \mathrm{~min}$ (SD 1.7, $\mathrm{p}<0.001$ ) was found. For research nurses, a non-significant mean difference of $-1.2 \mathrm{~min}$ (SD 3.8, $\mathrm{p}=0.207$ ) was found (table 2). Integrated registration of data of 300 patients per year would save around $€ 700$ salary costs per year, whereas

Table 2 Mean difference of registration time in the matched cohort study

Care and research
integrated versus
separate

\begin{tabular}{llr}
\cline { 2 - 3 } Mean difference & Minutes (SD) & P value \\
\hline Registration time & $-4.6(4.7)$ & 0.001 \\
Registration time resident & $-3.4(1.7)$ & $<0.001$ \\
$\begin{array}{l}\text { Registration time research } \\
\text { nurse }\end{array}$ & $-1.2(3.8)$ & 0.207 \\
\hline
\end{tabular}

for the implementation of the integrated registration computer system, an investment of $€ 10.000$ is estimated. The number of patients registered per year required to recover costs of implementing the integrated system is 1400 patients per year to recover costs in 3 years and 390 per year to recover costs in 10 years.

Table 3 Opinions of neurologists, general practitioners, rehabilitation physicians and specialists in geriatric medicine from both regions about the relevance of items in a typical discharge letter for a patient with cerebral ischaemia

\begin{tabular}{|c|c|c|}
\hline Item in discharge letter & $\begin{array}{l}\text { Assessed as } \\
\text { relevant } \\
n=62\end{array}$ & $\begin{array}{l}\text { Points in } \\
\text { quality } \\
\text { score }\end{array}$ \\
\hline $\begin{array}{l}\text { Duration of hospitalisation in days, } \\
\mathrm{n}(\%)\end{array}$ & $55(89)$ & \\
\hline \multicolumn{3}{|l|}{ Risk factors for $\mathrm{Cl}, \mathrm{n}(\%)$} \\
\hline Smoking & $61(98)$ & 100 \\
\hline Alcohol consumption & $60(97)$ & 100 \\
\hline Drug use & $59(95)$ & 100 \\
\hline Hypertension & $61(98)$ & 100 \\
\hline Hypercholesterolaemia & $61(98)$ & 100 \\
\hline Diabetes & $61(98)$ & 100 \\
\hline Atrial fibrillation & $61(98)$ & 100 \\
\hline Family history & $57(92)$ & 100 \\
\hline \multicolumn{3}{|l|}{ Data at time of admission, $\mathrm{n}(\%)$} \\
\hline NIHSS score & $38(61)$ & 50 \\
\hline mRS score & $25(40)$ & 50 \\
\hline $\begin{array}{l}\text { Treatment with intravenous } \\
\text { thrombolysis }\end{array}$ & $62(100)$ & 100 \\
\hline $\begin{array}{l}\text { Treatment with intra-arterial } \\
\text { thrombectomy }\end{array}$ & $62(100)$ & 100 \\
\hline DTNT intravenous thrombolysis & $32(52)$ & 50 \\
\hline DTNT intra-arterial thrombectomy & $32(52)$ & 50 \\
\hline \multicolumn{3}{|l|}{ Data at time of discharge, $\mathrm{n}(\%)$} \\
\hline Neurological examination & $58(94)$ & 100 \\
\hline NIHSS score & $27(44)$ & 50 \\
\hline mRS score & $24(39)$ & 50 \\
\hline TOAST classification of $\mathrm{Cl}$ & $29(47)$ & 50 \\
\hline $\begin{array}{l}\text { Complications directly related to } \\
\mathrm{Cl}\end{array}$ & $62(100)$ & 100 \\
\hline $\begin{array}{l}\text { Complications indirectly related } \\
\text { to } \mathrm{Cl}\end{array}$ & $62(100)$ & 100 \\
\hline Concluding diagnosis & $62(100)$ & 100 \\
\hline Medication at discharge & $62(100)$ & 100 \\
\hline Discharge destination & $62(100)$ & 100 \\
\hline $\begin{array}{l}\text { Appointments and policy after } \\
\text { discharge }\end{array}$ & $62(100)$ & 100 \\
\hline $\begin{array}{l}\text { Consequences of } \mathrm{Cl} \text { on driving } \\
\text { ability }\end{array}$ & $57(92)$ & 100 \\
\hline
\end{tabular}

$\mathrm{Cl}$, cerebral ischaemia; DTNT, door-to-needle time; NIHSS, National Institute of Health Stroke Scale; TOAST, Trial of Org 10172 in Acute Stroke Treatment; mRS, modified Rankin Scale. 
Table 4 Baseline characteristics of patients of whom discharge letters were studied

\begin{tabular}{|c|c|c|c|c|c|c|c|}
\hline \multirow[b]{2}{*}{ Characteristic } & \multirow{2}{*}{$\begin{array}{l}\text { Care and } \\
\text { research } \\
\text { separate, } 2011 \\
\text { Centre } A \\
n=100\end{array}$} & \multicolumn{2}{|c|}{$\begin{array}{l}\text { Care and research } \\
\text { integrated, } 2015 \\
\text { Centre A } \\
n=100\end{array}$} & \multicolumn{2}{|c|}{$\begin{array}{l}\text { Care and research } \\
\text { separate, } 2011 \\
\text { Centre } B \\
n=100\end{array}$} & \multicolumn{2}{|c|}{$\begin{array}{l}\text { Care and research } \\
\text { separate, } 2015 \\
\text { Centre B } \\
n=100\end{array}$} \\
\hline & & & P value* & & P value* & & P value* \\
\hline Women, n (\%)† & $35(35)$ & $41(41)$ & 0.382 & $44(44)$ & 0.193 & $43(43)$ & 0.246 \\
\hline Age, mean $(S D)^{\star}$ & $61(14)$ & $62(15)$ & 0.635 & $67(13)$ & 0.004 & $68(13)$ & 0.001 \\
\hline Smoking, $\mathrm{n}(\%) \dagger$ & $36(39) \ddagger$ & $44(47) \ddagger$ & 0.263 & $38(78) \S$ & $<0.001$ & $27(44) \S$ & 0.493 \\
\hline Alcohol, n (\%)† & $50(60) \ddagger$ & 58 (64)‡ & 0.059 & $22(73) \emptyset$ & 0.435 & $29(49) \S$ & 0.22 \\
\hline Drugs, $\mathrm{n}(\%) \dagger$ & $4(5) \ddagger$ & $4(4)$ & 1 & $0(0) e$ & 1 & $1(2) \S$ & 0.41 \\
\hline Known history of hypertension, $\mathrm{n}(\%) \dagger$ & $58(70) \ddagger$ & $46(50) \ddagger$ & 0.007 & $50(100)^{\star \star}$ & $<0.001$ & 37 (95)ף & 0.002 \\
\hline $\begin{array}{l}\text { Known history of hypercholesterolaemia, } \\
\mathrm{n}(\%)\end{array}$ & $58(74) \S$ & $35(39) \ddagger$ & $<0.001$ & $33(100) \uparrow$ & 0.001 & $16(94) \dagger \dagger$ & 0.075 \\
\hline Known history of diabetes, $\mathrm{n}(\%)$ & $16(21) \S$ & $12(14) \ddagger$ & 0.206 & $19(95) \Uparrow$ & $<0.001$ & 17 (85)ף & $<0.001$ \\
\hline Known history of atrial fibrillation, $\mathrm{n}(\%)$ & $11(92) \dagger \dagger$ & 8 (53)ף & 0.03 & $10(100) \S$ & 0.35 & $15(100) \ddagger$ & 0.255 \\
\hline Positive family history, n (\%) & $26(34) \S$ & $30(34) \ddagger$ & 0.946 & 7 (18)ף & 0.371 & 17 (63)ף & 0.009 \\
\hline NIHSS score, mean (SD)ł‡ & $4.7(4.9) \dagger \dagger$ & $4.8(4.3) \ddagger$ & 0.94 & $5.4(5.3) \ddagger$ & 0.652 & $6.6(5.3)$ १ & 0.284 \\
\hline \multicolumn{8}{|l|}{ TOAST, n (\%) } \\
\hline Large vessel & $27(39) \S$ & $26(30) \ddagger$ & 0.218 & $9(17)^{\star \star}$ & 0.007 & $13(25)^{\star \star}$ & 0.102 \\
\hline Small vessel & $6(9) \S$ & $18(20) \ddagger$ & 0.042 & $13(24)^{\star *}$ & 0.019 & $4(8)^{\star \star}$ & 0.843 \\
\hline Cardioembolic & $22(32) \S$ & 12 (14)‡ & 0.006 & $14(26)^{\star \star}$ & 0.471 & $17(33)^{\star \star}$ & 0.925 \\
\hline Other determined & $7(10) \S$ & $16(18) \ddagger$ & 0.158 & $5(9)^{\star \star}$ & 0.87 & $4(8)^{\star \star}$ & 0.642 \\
\hline Undetermined & $7(10) \S$ & $16(18) \ddagger$ & 0.158 & $13(24)^{\star \star}$ & 0.038 & $14(27)^{\star \star}$ & 0.016 \\
\hline $\begin{array}{l}\text { Direct complications related to } \mathrm{Cl}, \mathrm{n} \\
(\%) \dagger\end{array}$ & $5(7) \S$ & 2 (3)§ & 0.209 & $4(80)+\dagger$ & $<0.001$ & $4(80) \dagger †$ & $<0.001$ \\
\hline $\begin{array}{l}\text { Indirect complications related to } \mathrm{Cl}, \mathrm{n} \\
(\%)\end{array}$ & $16(21) \S$ & $14(18) \S$ & 0.684 & $10(91) \dagger †$ & $<0.001$ & 16 (89)†† & $<0.001$ \\
\hline \multicolumn{8}{|l|}{ Discharge destination, $\mathrm{n}(\%)$} \\
\hline Home & $44(50) \ddagger$ & 53 (54)‡ & 0.578 & 47 (53)‡ & 0.889 & 46 (52)‡ & 0.677 \\
\hline Nursing home & $13(15) \ddagger$ & $14(14)$ & 0.925 & $23(23) \ddagger$ & 0.134 & 27 (28)‡ & 0.034 \\
\hline Rehabilitation centre & $24(27) \ddagger$ & $15(15)$ & 0.045 & $26(30) \ddagger$ & 0.909 & $24(27) \ddagger$ & 0.665 \\
\hline Other hospital & 7 (8)‡ & $16(16)$ & 0.083 & $1(1) \ddagger$ & 0.02 & $1(1)$ & 0.02 \\
\hline
\end{tabular}

${ }^{*} P$ value is calculated with centre A 2011 as a reference.

†Percentages were calculated from the total number of patients without the missings.

$\ddagger 1 \%-20 \%$ missing data.

$\S 21 \%-40 \%$ missing data.

१61\%-80\% missing data.

${ }^{* *} 41 \%-60 \%$ missing data.

†† $81 \%-100 \%$ missing data.

$\ddagger \neq$ at time of cerebral ischaemia.

Cl, cerebral ischaemia; NIHSS, National Institute of Health Stroke Scale; TOAST, Trial of Org 10172 in Acute Stroke Treatment.

\section{Quality of the discharge letter}

The results of the survey among professionals rating the quality items in discharge letters are shown in table 3 (response rate of $47 \%$ ).

In total, 400 hospital discharge letters (100 for each cohort) were scored independently by two persons. With $1 \%$ initial disagreement in rating, the inter-rater reliability is very high (kappa 0.99). Table 4 shows the baseline characteristics of the cohorts with integrated and separate registration from 2011 and 2015.
The summed quality score of discharge letters from cohort 2015 with integrated registration was higher than the quality score of the cohort from the same year with separate registration (187.476 points vs 101.861 points, respectively; theoretical maximum 225.000 points) (figure 2). This corresponds to a mean difference in quality score per discharge letter between integrated and separate registration in 2015 of 856 points (SD 40.8, $\mathrm{p}<0.001$; with a maximum quality score per discharge letter of 2250 points). Noteworthy, the score in centre A 


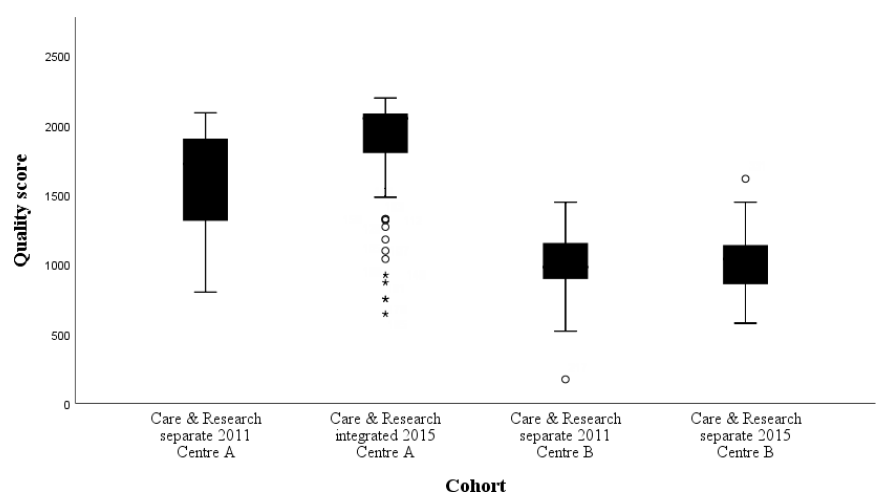

Figure 2 Total quality score for discharge letters in four cohorts (each covering 100 cases) representing two centres (integrated registration vs separate registration) and two time periods (before and after introducing integrated registration in centre A). $\mathrm{O}=$ outlier, ${ }^{*}=$ extreme

was already higher in 2011 when both centres had separate registration (mean difference of 597 points, SD 40.8, $\mathrm{p}<0.001)$. Integration of the registration was associated with an $18 \%$ increase in quality score in centre A but only a $2 \%$ increase in centre $B$ (figure 2 ). The mean difference in quality score between 2011 and 2015 was 282 points (SD 49.7, $\mathrm{p}<0.001$ ) for centre $\mathrm{A}$ and 23 points (SD 29.2, $\mathrm{p}=0.433$ ) for centre $\mathrm{B}$.

\section{DISCUSSION}

This study shows that within the Dutch PSI Cerebrovascular Disease Initiative, integrated registration of clinical and research data resulted in more efficiency, as well as higher quality of the discharge letter, as compared with separate registration.

We estimated that integrated registration of data of 300 patients per year would save around $€ 700$ salary costs annually. As the costs of implementing the integrated registration system require an investment of about $€ 10000$, integrated registration will only give a net saving in centres with high-volume registration.

The increase on quality, however, might be more substantial. We studied only the quality of the discharge letter, but quality effects on other aspects of clinical care and/or research might be much broader. A positive effect on clinical care of a research infrastructure like the PSI, in which clinical data are uniformly collected for research purposes, has been published previously. ${ }^{6}$ Such integration will support clinicians to adhere to standards of care, to collect all relevant clinical data and to standardise follow-up visits. ${ }^{6}$ No previous studies addressed these effects of integrated registration using quantitative research methods. A recent study in the UK evaluated the feasibility of a new template in the electronic patient record of the outpatient cardiac clinic for integrated registration of clinical and research using a survey among patients and referring general practitioners. ${ }^{7}$ It showed that the automatically generated clinical report from this template was valued highly by patients and referring general practitioners, whereas data from this template was immediately available for research purposes. ${ }^{7}$ These results support the notion that structured registration of clinical data contributes to a higher quality of information in both clinical care and research. We hypothesise that integrated registration results in improved quality of discharge letters mainly by leading to more complete, structured and uniform discharge letters in which the recipient of these discharge letters can easily find the important information to further care for the patient.

Our comparative matched cohort study was performed by local professionals experienced in stroke care who were blinded for case characteristics. This enabled independent time recording of all registration activities of both the residents and the research nurses. Alternative procedures (eg, automated recording of computer time and/or recording actual registration in real practice) were considered unfeasible. A fair representation of cases was included in both centres matched on items that might influence registration time. Another strength of our study is that one resident, who has performed clinical work in both centres, performed the registration. For the research nurses, both with $>10$ years of experience, such a combined role was not possible, acknowledging that the effect of the registration procedure might have been confounded by personal characteristics of the two nurses.

A learning effect for the resident is unlikely to explain shorter registration time, since we started registration in centre $\mathrm{A}$ with the shortest registration time. In addition, the shorter registration time in centre A cannot be explained by differences in case mix between centres as the cases in centre A were generally more complex (more investigations and longer stay in the hospital). Most of the difference in registration time between centres was attributed to the resident performance in both centres. Even though having a single resident perform the registration is a strength of our study, it is also a potential limitation since it could introduce bias if that resident favours one participating centre. A smaller difference in registration time was observed between research nurses, probably because their duties were much more comparable in both centres, that is, checking every item in both registration methods. We cannot exclude positive effects of integrated registration on the level of the research nurse, but our study was not designed to demonstrate this. Another limitation of our study is that not all costs associated with implementing the integrated system could be taken into account as these might vary between different centres and countries. Future cost effectiveness studies should further investigate the effects of integrated registration, but this will be expensive and time-consuming, given the long duration of follow-up needed to determine quality-adjusted life years (QALY).

Our analyses on the quality of the discharge letter were based on quality parameters validated by the expert opinion of a substantial, interdisciplinary group of 
recipients of these kinds of discharge letters. These professionals were recruited from both regions to avoid biased scores. Double rating these quality scores produced high inter-rater reliability. It should be noted that the quality score does not cover all elements of a discharge letter, only those included in the online survey.

This study demonstrated that integrated registration is associated with a much better quality of the discharge letter. Part of the difference was already present in 2011, the year prior to the introduction of the integrated registration. This might be a reflection of the fact that centre A by that time already preluded such an integrated system.

\section{CONCLUSION}

We conclude that integrated registration of clinical and research data in patients with cerebral ischaemia is associated with increased time efficiency, some decrease in salary costs and a substantial increase in the quality of the discharge letter. Because of these and other positive effects on quality of both clinical care and research data, we recommend integrated registration. Reduction in costs becomes of interest only in situations of highvolume registration, due to the initial investments needed to adopt the registration software.

\section{Author affiliations}

${ }^{1}$ Department of Neurology, University Medical Center Utrecht Brain Center, Utrecht, The Netherlands

${ }^{2}$ Department of Neurology, University Medical Center Groningen, Groningen, The Netherlands

${ }^{3}$ Department of Health Technology and Services Research, Universiteit Twente, Enschede, The Netherlands

${ }^{4}$ Department for Health Evidence, Radboud University Medical Centre, Nijmegen, The Netherlands

Contributors YMR, LJK, GAZ and HK conceived the study. YMR, LJK, GAZ, HK and LAM were involved in protocol development and searched the literature. LAM was involved in gaining ethical approval and patient recruitment. LAM, G-JL and JEB were involved in data collection. All authors were involved in data analysis. All authors reviewed, edited and approved the final version of the manuscript.

Funding This study was sponsored by a grant from the Dutch Parelsnoer Institute. Competing interests None.

Patient consent for publication Not required.

Ethics approval This study was approved by the Medical Ethical Review Committee, University Medical Center Utrecht (approval number 16-500).

Provenance and peer review Not commissioned; externally peer reviewed. Data availability statement Data are available upon reasonable request.

Open access This is an open access article distributed in accordance with the Creative Commons Attribution Non Commercial (CC BY-NC 4.0) license, which permits others to distribute, remix, adapt, build upon this work non-commercially, and license their derivative works on different terms, provided the original work is properly cited, appropriate credit is given, any changes made indicated, and the use is non-commercial. See: http://creativecommons.org/licenses/by-nc/4.0/.

\section{REFERENCES}

1. The Dutch Parelsnoer Institute. Parelsnoer, 2017. Available: http:// parelsnoer.org/page/nl/ [Accessed 10 Dec 2017].

2. Manniën J, Ledderhof T, Verspaget HW, et al. The Parelsnoer Institute: a national network of standardized clinical biobanks in the Netherlands. Open J Bioresour 2017;4.

3. Talmon JL, Ros' MG, Legemate DA. PSI: The Dutch academic infrastructure for shared biobanks for translational research. Summit Trans/ Bioinform 2008;2008:110-4.

4. National Institute of Neurological Disorders and Stroke. Free versions of the NIH stroke scale (NIHSS), 2016. Available: https://www.ninds. nih.gov/Stroke-Scales-and-Related-Information [Accessed $10 \mathrm{Apr}$ 2018].

5. Adams HP, Bendixen BH, Kappelle LJ, et al. Classification of subtype of acute ischemic stroke. Definitions for use in a multicenter clinical trial. TOAST. trial of ORG 10172 in acute stroke treatment. Stroke 1993;24:35-41.

6. Douglas CMW, Scheltens P. Rethinking biobanking and translational medicine in the Netherlands: how the research process stands to matter for patient care. Eur J Hum Genet 2015;23:736-8.

7. Bodagh N, Archbold RA, Weerackody R, et al. Feasibility of realtime capture of routine clinical data in the electronic health record: a hospital-based, observational service-evaluation study. BMJ Open 2018;8:e019790. 